\title{
MATHEMATICAL CORRELATIONS FOR DESCRIBING SOLUTE TRANSFER INTO FUNCTIONALIZED ALKANE SOLVENTS CONTAINING HYDROXYL, ETHER, ESTER OR KETONE SOLVENTS
}

Laura M. Grubbs ${ }^{\mathrm{a}}$, Mariam Saifullah ${ }^{\mathrm{a}}$, Nohelli E. De La Rosa ${ }^{\mathrm{a}}$, Shulin Ye ${ }^{\mathrm{a}}$, Sai S. Achi ${ }^{\mathrm{a}}$, William E. Acree, Jr. a $^{*}$ and Michael H. Abraham ${ }^{\mathrm{b}}$

a Department of Chemistry, 1155 Union Circle Drive \#305070, University of North Texas, Denton, TX 76203-5017 (USA)

${ }^{\mathrm{b}}$ Department of Chemistry, University College London, 20 Gordon Street, London, WC1H 0AJ (UK)

\begin{abstract}
Gas-to-liquid and water-to-liquid partition coefficients have been compiled for more than 2800 different solute-solvent combinations. Solutes considered include acyclic monofunctional alkanols, dialkyl ethers, alkyl alkanoates and alkanones, as well difunctional alkoxyalcohols. Both sets of partition coefficients were analyzed using the Abraham solvation parameter model with fragment-specific equation coefficients. The derived equations correlated the experimental gas-to-alcohol and water-to-alcohol partition coefficient data to within 0.15 and $0.16 \log$ units, respectively. The fragment-specific equation coefficients that have been calculated for the $\mathrm{CH}_{3}$, $\mathrm{CH}_{2}, \mathrm{CH}, \mathrm{C}, \mathrm{OH}, \mathrm{O}, \mathrm{C}(\mathrm{O}) \mathrm{O}$ and $\mathrm{C}=\mathrm{O}$ fragment groups can be combined to yield expressions capable of predicting the partition coefficients of solutes in other anhydrous alkanol, dialkyl ether, alkyl alkanolate, alkanone and alkoxyalkanol solvents.
\end{abstract}


KEY WORDS AND PHRASES: Partition coefficients, Predictive methods, Infinite dilution activity coefficients, Solubilities, Linear free energy relationships

* Corresponding author, Tel: +1 940565 3543; fax: +1 940565 4318; e-mail address: acree@unt.edu 


\section{INTRODUCTION}

This study continues our examination of the applicability of the Abraham Solvation model in describing solute processes having chemical, environmental and pharmaceutical importances. Previous studies have documented that the basic model provides reasonably accurate mathematical descriptions for the transfer of organic solutes into both conventional organic solvents [1-11] and ionic liquid solvents [12,13] from water and from the gas phase, for the partitioning of drug molecules between blood and select body organs [14-18], and for estimating nasal pungency thresholds $[19,20]$ and Draize scores and eye irritation thresholds $[19,21]$ of compounds. Each of the predicted properties involves either direct or indirect solute partitioning processes.

The documented success of the model to so many different types of processes prompted us to explore ways to increase the model's applicability. For partitions into ionic liquids, Sprunger et al. [22-24] split each of the equation coefficients into a cation-specific and anionspecific contribution

$\log \mathrm{K}=\mathrm{c}_{\text {cation }}+\mathrm{c}_{\text {anion }}+\left(\mathrm{e}_{\text {cation }}+\mathrm{e}_{\text {anion }}\right) \mathbf{E}+\left(\mathrm{s}_{\text {cation }}+\mathrm{s}_{\text {anion }}\right) \mathbf{S}+\left(\mathrm{a}_{\text {cation }}+\mathrm{a}_{\text {anion }}\right) \mathbf{A}+$

$$
\left(\mathrm{b}_{\text {cation }}+\mathrm{b}_{\text {anion }}\right) \mathbf{B}+\left(\mathrm{l}_{\text {cation }}+\mathrm{l}_{\text {anion }}\right) \mathbf{L}
$$

and

$\log \mathrm{P}=\mathrm{c}_{\text {cation }}+\mathrm{c}_{\text {anion }}+\left(\mathrm{e}_{\text {cation }}+\mathrm{e}_{\text {anion }}\right) \mathbf{E}+\left(\mathrm{s}_{\text {cation }}+\mathrm{s}_{\text {anion }}\right) \mathbf{S}+\left(\mathrm{a}_{\text {cation }}+\mathrm{a}_{\text {anion }}\right) \mathbf{A}+$

$$
\left(\mathrm{b}_{\text {cation }}+\mathrm{b}_{\text {anion }}\right) \mathbf{B}+\left(\mathrm{v}_{\text {cation }}+\mathrm{v}_{\text {anion }}\right) \mathbf{V}
$$


in describing the logarithms of the gas-to-ionic liquid (IL) partition coefficients, $\log \mathrm{K}$, and of the water-to-IL partition coefficients, $\log \mathrm{P}$, in a data set containing more than 2,000 experimental values. A similar idea, but this time using a fragment based method, was used to describe partitions into acyclic monofunctional alcohol solvents [25]

$$
\begin{aligned}
\log K= & \sum_{\text {frag }} n_{\text {frag }} c_{\text {frag }}+\sum_{\text {frag }} n_{\text {frag }} e_{\text {frag }} \mathrm{E}+\sum_{\text {frag }} n_{\text {frag }} s_{\text {frag }} \mathrm{S}+\sum_{\text {frag }} n_{\text {frag }} a_{\text {frag }} \mathrm{A}+\sum_{\text {frag }} n_{\text {frag }} b_{\text {frag }} \mathrm{B} \\
& +\sum_{\text {frag }} n_{\text {frag }} l_{\text {frag }} \mathrm{L}
\end{aligned}
$$

and

$$
\begin{aligned}
\log P= & \sum_{\text {frag }} n_{\text {frag }} c_{\text {frag }}+\sum_{\text {frag }} n_{\text {frag }} e_{\text {frag }} \mathrm{E}+\sum_{\text {frag }} n_{\text {frag }} s_{\text {frag }} \mathrm{S}+\sum_{\text {frag }} n_{\text {frag }} a_{\text {frag }} \mathrm{A}+\sum_{\text {frag }} n_{\text {frag }} b_{\text {frag }} \mathrm{B} \\
& +\sum_{\text {frag }} n_{\text {frag }} v_{\text {frag }} \mathrm{V}
\end{aligned}
$$

where $\mathrm{n}_{\text {frag }}$ represents the number of times the given fragment group appears in the alcohol solvent, and the "frag" subscript on each of the seven equation coefficients (c, e, s, a, b, l and v) indicates that the value pertains to fragment group. Fragment-specific equation coefficients were reported for $\mathrm{CH}_{3}, \mathrm{CH}_{2}, \mathrm{CH}, \mathrm{C}$ and $\mathrm{OH}$ functional groups. Revelli et al. [26] employed the equations

$$
\begin{gathered}
\log K=\sum_{\text {group }} c_{i} n_{i}+\sum_{\text {group }} e_{i} n_{i} E+\sum_{\text {group }} s_{i} n_{i} S+\sum_{\text {group }} a_{i} n_{i} A+\sum_{\text {group }} b_{i} n_{i} B+\sum_{\text {group }} l_{i} n_{i} L+ \\
\left(c_{\text {anion }}+e_{\text {anion }} E+s_{\text {anion }} S+a_{\text {anion }} A+b_{\text {anion }} B+l_{\text {anion }} L\right)
\end{gathered}
$$

and

$$
\begin{gathered}
\log P=\sum_{\text {group }} c_{i} n_{i}+\sum_{\text {group }} e_{i} n_{i} E+\sum_{\text {group }} s_{i} n_{i} S+\sum_{\text {group }} a_{i} n_{i} A+\sum_{\text {group }} b_{i} n_{i} B+\sum_{\text {group }} v_{i} n_{i} V+ \\
\left(c_{\text {anion }}+e_{\text {anion }} E+s_{\text {anion }} S+a_{\text {abion }} A+b_{\text {anion }} B+v_{\text {anion }} V\right)
\end{gathered}
$$


which are a combination of the two approaches in describing solute transfer into Il solvents. The cation coefficients were further split into functional group values, while the anion-specific values remained intact. In each study, the authors noted that very little loss in predictive ability resulted from splitting the Abraham model equation coefficients into ion-specific and/or fragmentspecific values.

The independent variables, or descriptors, in Eqns. $1-6$ are solute properties as follows: $\mathbf{E}$ and $\mathbf{S}$ refer to the excess molar refraction and dipolarity/polarizability descriptors of the solute, respectively, $\mathbf{A}$ and $\mathbf{B}$ are measures of the solute hydrogen-bond acidity and basicity, $\mathbf{V}$ is the McGowan volume of the solute and $\mathbf{L}$ is the logarithm of the solute gas phase dimensionless Ostwald partition coefficient into hexadecane at $298 \mathrm{~K}$. (A listing of all of the symbols is found in Table S1 in the Supporting Information.) The first four descriptors can be regarded as measures of the tendency of the given solute to undergo various solute-solvent interactions. The latter two descriptors, $\mathbf{V}$ and $\mathbf{L}$, are both measures of solute size, and so will be measures of the solvent cavity term that will accommodate the dissolved solute. General dispersion interactions are also related to solute size, hence, both $\mathbf{V}$ and $\mathbf{L}$ will also describe the general solute-solvent interactions.

The regression coefficients and constants (c, e, s, a, b, l and v) are obtained by regression analysis of experimental data for a given process (i.e., a given partitioning process or a given chromatographic stationary phase and mobile phase combination, etc.). In the case of partition coefficients, where two solvent phases are involved, the c, e, s, a, b, 1 and v coefficients represent differences in the solvent phase properties. For any fully characterized system/process (those with calculated values for the equation coefficients) further values of $\log \mathrm{K}$ and $\log \mathrm{P}$ can be estimated with known values for the descriptors. This is the major advantage of using Eqns. $1-$ 
6 to correlate solute partitioning process having chemical, environmental and pharmaceutical importance. The predictive ability is what prompted us to explore whether one could develop a group estimation method for the equation coefficients based on group contribution concepts. As previously stated [27] any such group contribution is not intended to replace the solvent-specific Abraham model correlations that we have developed and will continue to develop in the future. Rather, group contribution methods are to provide researchers with a means to make reasonably accurate predictions in select solvent classes for which solvent-specific correlations have not been developed.

In the present study we extend our proposed fragment-specific equation coefficient approach to include acyclic monfuncational dialkyl ether, alkyl alkanoate and alkanone solvents, as well as alkoxyalkanols. The latter solvent class contains two functional (an ether and a hydroxyl group). Published $\log \mathrm{K}$ and $\log \mathrm{P}$ data for solutes dissolved in alkoxyalkanols is scarce. To increase the number of experimental values we have measured solubilities for 3methylbenzoic acid, salicylamide, biphenyl, 4-nitrobenzoic acid, 2-methoxybenzoic acid, 4methoxybenzoic acid, 4-chlorobenzoic acid and 4-hydroxyacetanilide in 2-ethoxyethanol, 2propoxyethanol, 2-butoxyethanol, 2-isopropoxyethanol, 3-methoxy-1-butanol and 1-tert-butoxy2-propanol. In total 45 additional experimental solubilities were measured for use in the fragment-specific equation coefficient computations. Our preliminary observations [27] regarding the extension of the proposed fragment approach were communicated earlier in response to comments made by Endo and Goss. [28] The authors had correctly noted that it was possible to describe mathematically $\log \mathrm{K}$ and $\log \mathrm{P}$ data for solutes in anhydrous alkanol solvents with fewer equation coefficients. The correlation given by Endo and Goss was specific to monofunctional alkanol solvents and the authors made no mention of whether their method 
might be extendable to other solvent classes. Our intent was to develop a group contribution method that could be applied to other classes of organic solvents, rather than to simply describe experimental $\log \mathrm{K}$ and $\log \mathrm{P}$ data for a single solvent class with a minimum number of regression coefficients. The brief preliminary observations [27] did not consider water-toorganic solvent partition coefficients and alkanone solvents, and did not include the 45 additional experimental solubilities in alkoxyalkanone solvents that were measured as part of the present study.

\section{EXPERIMENTAL METHOD}

3-Methylbenzoic acid (Aldrich $99 \%$ ), salicylamide (Aldrich > $99 \%$ ), 4-nitrobenzoic acid (Across > $99 \%$ ), 2-methoxybenzoic acid (Aldrich > $99 \%$ ), 4-methoxybenzoic acid (Aldrich > $99 \%$ ), 4-chlorobenzoic acid (Across $99 \%$ ), biphenyl (Aldrich $99 \%$, recrystallized from anhydrous methanol), and 4-hydroxyacetanillide (Sigma $99 \%$ ) were purchased from commercial sources. 2-Ethoxyethanol (Aldrich $99 \%$ ), 2-propoxyethanol (Aldrich > $99 \%$ ), 2-butoxyethanol (Across > $99 \%$ ), 2-isopropoxyethanol (Aldrich 99\%), 3-methoxy-1-butanol (Aldrich $99 \%$ ) and 1-tert-butoxy-2-propanol (Aldrich $99 \%$ ) were stored over molecular sieves and distilled shortly before use. Gas chromatographic analysis showed solvent purities to be 99.7 mole percent or better.

Excess solute and alkoxyalkanol solvent were placed in amber glass bottles and allowed to equilibrate in a constant temperature water bath at $298.15 \pm 0.1 \mathrm{~K}$ for at least 3 days with periodic agitation. After equilibrium, the samples stood unagitated for several hours in the constant temperature bath to allow any finely dispersed particles to settle. Attainment of equilibrium was verified by both repetitive measurements the following day (or sometimes after 
2 days) and by approaching equilibrium from supersaturation by pre-equilibrating the solution at a slightly higher temperature. Aliquots of the respective saturated solutions were transferred through a coarse filter into a tared volumetric flask to determine the amount of sample and diluted quantitatively with methanol (or 2-propanol) for spectrophotometric analysis on a Melton Roy Spectronic 1001 Plus spectrophotometer. Concentrations of the diluted solutions were determined from a Beer-Lambert law absorbance versus concentration working curve for nine standard solutions of known concentration. The analysis wavelengths and concentration ranges used for each solute have been reported in earlier solubility publications. [29-33]

Experimental molar concentrations were converted to (mass/mass) solubility fractions by multiplying by the molar mass of the solute, volume(s) of the volumetric flasks used and any dilutions required to place the measured absorbances on the Beer-Lambert law absorbance versus concentration working curve, and then dividing by the mass of the saturated solution analyzed. Mole fraction solubilities were computed from solubility mass fractions using the molar masses of the solutes and alkoxyalkanol solvents. Experimental mole fraction solubilities, $\mathrm{X}_{\mathrm{S}}{ }^{\text {sat }}$, are tabulated in Table 1 the solute-solvent systems studied. Numerical values represent the average of between four and eight independent determinations, and were reproducible to within $\pm 1.5 \%$.

\section{PARTITION COEFFICIENT DATABASES}

The majority of the experimental partition coefficient data ( $\log \mathrm{K}$ and $\log \mathrm{P}$ values) was taken from our earlier publications $[1-4,10,11,25]$ that reported solvent-specific Abraham model correlations. Added to the database are numerical values for solutes dissolved in alkoxyalkanol solvents. The added values were calculated from 


$$
\begin{aligned}
& \log K=\log \left(\frac{R T}{\gamma_{\text {solute }}^{\infty} P_{\text {solute }}^{o} V_{\text {solvent }}}\right) \\
& \log K=\log \left(\frac{R T}{K_{\text {Henry }} V_{\text {solvent }}}\right)
\end{aligned}
$$

from experimental infinite dilution activity coefficient, $\gamma_{\text {solute }}{ }^{\infty}$, and Henry's law constants, $\mathrm{K}_{\mathrm{Henry}}$, for gases dissolved in anhydrous alkoxyalkanol solvents. [34-38] In Eqns. 7 and 8 R is the universal gas constant, $\mathrm{T}$ is the system temperature, $\mathrm{P}_{\text {solute }}{ }^{\circ}$ is the vapor pressure of the solute at $\mathrm{T}$, and $\mathrm{V}_{\text {solvent }}$ is the molar volume of the solvent. The calculation of $\log \mathrm{P}$ requires

$$
\log \mathrm{P}=\log \mathrm{K}-\log \mathrm{K}_{\mathrm{w}}
$$

knowledge of the solute's gas phase partition coefficient into water, $\mathrm{K}_{\mathrm{w}}$, which is available for most of the solutes being studied.

In the case of crystalline solutes, the partition coefficient between water and the anhydrous organic solvent is calculated as a solubility ratio

$$
\log \mathrm{P}=\log \left(\mathrm{C}_{\mathrm{S}} / \mathrm{C}_{\mathrm{W}}\right)
$$

of the solute's molar solubilities in the organic solvent, $\mathrm{C}_{\mathrm{S}}$, and in water, $\mathrm{C}_{\mathrm{W}}$. Molar solubilities can also be used to calculate $\log \mathrm{K}$ values, provided that the equilibrium vapor pressure of the solute above crystalline solute, $\mathrm{P}_{\text {solute }}{ }^{\circ}$, at $298 \mathrm{~K}$ is also available. $\mathrm{P}_{\text {solute }}{ }^{\circ}$ can be transformed into the gas phase concentration, $\mathrm{C}_{\mathrm{G}}$, and the gas-to-water and gas-to-organic solvent partitions, $\mathrm{K}_{\mathrm{W}}$ and $\mathrm{K}$, can be obtained through the following equations

$$
\log \mathrm{K}_{\mathrm{W}}=\log \left(\mathrm{C}_{\mathrm{W}} / \mathrm{C}_{\mathrm{G}}\right) \quad \text { or } \quad \log \mathrm{K}=\log \left(\mathrm{C}_{\mathrm{S}} / \mathrm{C}_{\mathrm{G}}\right)
$$


The vapor pressure and aqueous solubility data needed for these calculations are reported in our previous publications. For convenience we have listed in Tables S1 and S2 (Supporting Information) the numerical $\log \mathrm{K}$ and $\log \mathrm{P}$ values that were used in computing the Abraham model fragment-specific equation coefficients.

Molecular solute descriptors for all of the compounds considered in the present are also tabulated in Tables S2 and S3. The tabulated values came from our solute descriptor database, and were obtained using various types of experimental data, including water-to solvent partitions, gas-to-solvent partitions, solubility and chromatographic retention data. [39-41]

\section{RESULTS AND DISCUSSION}

Our search of the published chemical literature, combined with the experimental data in Table 1, yielded 2790 experimental $\log \mathrm{K}$ and 2826 experimental $\log \mathrm{P}$ values for solutes dissolved in anhydrous (dry) alkanol, dialkyl ether, alkyl alkanoate, alkanone and alkoxyalkanol solvents. The solutes considered cover a reasonably wide range of compound types and descriptor values. The experimental $\log \mathrm{K}$ data in Table S2 (Supporting Information) and $\log \mathrm{P}$ data in Table S3 (Supporting Information) were analyzed in accordance with Eqn. 3 ( N = 2790, $\mathrm{SD}=0.149, \mathrm{R}^{2}=1.000$ and $\left.\mathrm{F}=123,218\right)$ and Eqn. $4\left(\mathrm{~N}=2826, \mathrm{SD}=0.162, \mathrm{R}^{2}=0.998\right.$ and 26,792) of our proposed Abraham model with fragment-specific equation coefficients. Numerical values of the calculated fragment groups are tabulated in Tables 2 and 3, along with their respective errors (given in parentheses immediately below each equation coefficient). The fragment values in Tables 2 and 3 are strictly curve-fitting coefficients and are intended to encode chemical information. Here and elsewhere, $\mathrm{N}$ corresponds to the number of data points, 
$\mathrm{R}_{2}$ denotes the squared correlation coefficient, $\mathrm{SD}$ is the standard deviation and $\mathrm{F}$ refers to the Fisher F-statistic. The statistics of both correlations are quite good as evidenced by the near unit values of the squared correlation coefficients and by the small standard deviations of $\mathrm{SD}=0.149$ (Eqn. 3) and SD $=0.162$ (Eqn. 4) $\log$ units. See Figures S1 and S2 (Supporting Information) for plots of the calculated $\log \mathrm{K}$ and $\log \mathrm{P}$ values based on Eqns. 3 and 4 against observed data. The experimental $\log \mathrm{K}$ and $\log \mathrm{P}$ values cover ranges of about 36.2 and $19.1 \log$ units, respectively.

We have retained our initial fragmentation scheme: $\mathrm{CH}_{3}, \mathrm{CH}_{2}, \mathrm{CH}, \mathrm{C}$ and $\mathrm{OH}$ groups; plus three new groups that are included to extend the method to dialkyl ether (-O-), alkyl alkanoate $(-\mathrm{C}(\mathrm{O}) \mathrm{O}-)$ and alkanone $(\mathrm{C}=\mathrm{O})$ solvents. Using our fragmentation scheme the alkanone solvent 4-methyl-2-pentaone is composed of $3 \mathrm{CH}_{3}$ fragment groups, $1 \mathrm{CH}_{2}$ fragment group, $1 \mathrm{CH}$ fragment group and $1 \mathrm{C}=\mathrm{O}$ fragment group.

As part of our data analyses, we estimated how much descriptive ability was likely lost as the result of separating the Abraham model coefficients into fragment-specific values. Abraham model correlations have been reported within the past 2 years for 14 of the alkanol [1,2,], 3 of the alkyl alkanoate [3], and 2 of the alkanone [4] solvents considered here. Our existing Abraham model correlations $[10,11]$ for anhydrous diethyl ether and anhydrous dibutyl ether are much older, and were based on the limited experimental data that was available back in 2003 when the equations were published. The data bases used in the diethyl ether and dibutyl ether analysis had very few acidic solutes. Fair comparisons require that the data sets be as similar as possible. We have reanalyzed the experimental data for three of the dialkyl ether solvents to yield:

\section{Diethyl ether}

$\log \mathrm{K}=0.288(0.033)-0.379(0.057) \mathbf{E}+0.904(0.069) \mathbf{S}+2.937(0.075) \mathbf{A}+0.963(0.012) \mathbf{L}$ 


$$
\left(\mathrm{N}=71, \mathrm{R}^{2}=0.998, \mathrm{SD}=0.139, \mathrm{~F}=9645\right)
$$

$\log \mathrm{P}=0.350(0.044)+0.358(0.051) \mathbf{E}-0.820(0.083) \mathbf{S}-0.588(0.080) \mathbf{A}-4.956(0.121) \mathbf{B}$

$$
\begin{aligned}
& +4.350(0.051) \mathbf{V} \\
& \left(\mathrm{N}=71, \mathrm{R}^{2}=0.994, \mathrm{SD}=0.153, \mathrm{~F}=2101\right)
\end{aligned}
$$

\section{Dibutyl ether}

$\log \mathrm{K}=0.153(0.051)-0.406(0.087) \mathbf{E}+0.758(0.109) \mathbf{S}+2.152(0.124) \mathbf{A}-0.610(0.145) \mathbf{B}$

$$
+1.008(0.015) \mathbf{L}
$$

$$
\left(N=62, R^{2}=0.996, S D=0.184, F=2978\right)
$$

$\log \mathrm{P}=0.176(0.053)+0.394(0.072) \mathbf{E}-0.985(0.098) \mathbf{S}-1.414(0.111) \mathbf{A}-5.357(0.130) \mathbf{B}$

$$
\begin{aligned}
& +4.524(0.051) \mathrm{V} \\
& \left(\mathrm{N}=65, \mathrm{R}^{2}=0.995, \mathrm{SD}=0.169, \mathrm{~F}=2368\right)
\end{aligned}
$$

\section{Methyl tert-butyl ether}

$\log \mathrm{K}=0.231(0.044)-0.536(0.060) \mathbf{E}+0.890(0.077) \mathbf{S}+2.623(0.101) \mathbf{A}+0.999(0.008) \mathbf{L}$

$$
\left(\mathrm{N}=50, \mathrm{R}^{2}=0.998, \mathrm{SD}=0.136, \mathrm{~F}=5568\right)
$$

$\log \mathrm{P}=0.341(0.070)+0.307(0.079) \mathbf{E}-0.817(0.115) \mathbf{S}-0.618(0.125) \mathbf{A}-5.097(0.146) \mathbf{B}$

$$
\begin{aligned}
& +4.425(0.039) \mathbf{V} \\
& \left(\mathrm{N}=52, \mathrm{R}^{2}=0.998, \mathrm{SD}=0.176, \mathrm{~F}=4341\right)
\end{aligned}
$$


The $\mathbf{b} \cdot \mathbf{B}$ term was insignificant in the $\log \mathrm{K}$ correlations for both diethyl ether and methyl tertbutyl ether and has been removed from the final correlation. Each of the derived correlations is statistically very good, with standard deviations ranging from $\mathrm{SD}=0.136$ to $\mathrm{SD}=0.184 \log$ units.

Equations $12-17$, along with our recently published Abraham model correlations for linear alcohols [2], secondary and branched alcohols [1], alkyl alkanoates [3] and alkanones [4], provide the benchmark computations used in assessing how much predictive accuracy might be lost in splitting the equation coefficients into fragment-specific values. There has been one major change since the linear alcohol correlations were published. Thirty-nine additional log $\mathrm{P}$ values have been added to the database. Since the additional values were included in the regression analysis in calculating the fragment-specific equation coefficients listed in Table 3, we did recalculate the standard deviation for the ethanol $\log \mathrm{P}$ correlation with the 39 new values included. The standard deviation decreased slightly, from $\mathrm{SD}=0.158$ to $\mathrm{SD}=0.151$. To have a common basis for comparison, the deviations between observed and calculated values were expressed as

$$
D e v=\sqrt{\frac{\left(\log K_{c a l c}-\log K_{o b s}\right)^{2}}{N-6}}
$$

For the majority of the 22 solvents considered, there was only a slight loss (less than $0.03 \log$ units) in predictive ability noted in splitting the equation coefficients into fragment-specific values as shown in Figures 1 and 2. The two notable exceptions are diethyl ether and dibutyl ether. In the case of dibutyl ether the standard errors in both the $\log \mathrm{K}$ and $\log \mathrm{P}$ calculations increased by $0.08 \log$ units, with the calculations for 4-hydroxyacetanilide accounting for a significant part of the increase. The predicted $\log \mathrm{K}$ and $\log \mathrm{P}$ values differ from by the 
experimental values by 1.1 and $1.0 \log$ units. In both cases the correlations predicted a higher experimental solubility. We did remeasure the solubility of 4-hydroxyacetanilide in dibutyl ether and obtained essentially the same $\log$ molar solubility $(\log C s=-3.16)$ as before $(\log C s=-3.14$ [11]). The only explanation that we can offer for why the predicted values are so far off is perhaps 4-hydroxyacetanilide existed in a different crystalline phase in dibutyl ether. Despite the increased standard errors noted in the diethyl ether and dibutyl ether calculations, we believe that the predictive accuracy in our fragment-specific equation coefficient method is sufficient to allow researchers to make reasonably accurate predictions of gas-to-liquid and water-to-liquid partition coefficients for solutes dissolved in simple alkoxyalcohols and in acyclic monofunctional alkanol, dialkyl ether, alkyl alkanoate and alkanone solvents, provided that the solvents are similar to those studied here. The coefficients should not be used for other classes of organic solvents.

Readers are reminded that the motivation behind developing a fragment or group contribution method for estimating the Abraham model equation coefficients is not to predict partition coefficients of solutes in solvents for which we already have good $\log \mathrm{K}$ and $\log \mathrm{P}$ correlations. Equations 12 and 13 should be used in predicting partition coefficients in diethyl ether, Eqns. 14 and 15 should be used in predicting partition coefficients for solutes dissolved in dibutyl ether, and not the fragment-specific correlations based on Eqns. 3 and 4. The fragmentspecific model could be used though to predict solute transfer into solvents, such as the alkoxyalkanol solvents, for which there is not sufficient experimental data to develop meaningful Abraham model correlations. The maximum number of experimental values that we have for any alkoxyalkanol solvent (for 2-ethoxyethanol) is $26 \log \mathrm{K}$ and $\log \mathrm{P}$ values, and the number is much less for 2-isopropoxyethanl (11 values), 3-methoxy-1-butanol (10 values) and 1-tert- 
butoxy-2-propanol (8 values). Equation 3 (with the equation coefficients in Table 2) predicts the $\log \mathrm{K}$ values for 2-ethoxyethanol to within a standard error of $\mathrm{SE}=0.10 \log$ units. Similarly, Eqn. 4 predicts the $\log \mathrm{P}$ values for solutes dissolved in 2-ethoxyethanol to within a standard error of $\mathrm{SE}=0.14 \log$ units. This is comparable in magnitude to the standard errors associated with many of the solvent-specific Abraham model correlations that we have reported in the past (see Eqns. $12-17$ ).

The fragment-specific equation coefficients reported in Tables 2 and 3 will also allow us to calculate solute descriptors of additional organic compounds. There is published solubility data in the chemical and pharmaceutical literature for organic nonelectrolytes and organic salts dissolved in alkanol, alkyl alkanoate and alkanone solvents for which Abraham model correlations have not yet been developed. The fragment-specific equation coefficients reported in Tables 2 and 3 allow us to generate $\log \mathrm{P}$ and $\log \mathrm{K}$ correlations for such solvents like methyl isobutyl ketone, 2-pentanone and tert-pentanol that can be used in combination with published solubility data in these solvents to calculate solute descriptors.

\section{CONCLUSION}

Our methodology of splitting the Abraham model equation coefficients into fragmentspecific values has been successfully extended to acyclic monofunctional alkanol, dialkyl ether, alkyl alkanoate and alkanone solvents, as well as to alkoxyalkanol solvents. Fragment-specific equation coefficients have been calculated for the $\mathrm{CH}_{3}, \mathrm{CH}_{2}, \mathrm{CH}, \mathrm{C}, \mathrm{OH}, \mathrm{O}, \mathrm{C}(\mathrm{O}) \mathrm{O}$ and $\mathrm{C}=\mathrm{O}$ functional groups. The fragment-specific equation coefficients can be summed to yield Abraham model correlations for predicting partition coefficients describing solute transfer from both the gas phase and from water to anhydrous solvents containing either a single hydroxyl, ether, ester 
or ketone functional group, or to alkoxyalkanol solvents. The latter solvent class contains both a hydroxyl and ether functional group. The derived correlation equations were found to describe the $\log \mathrm{K}$ and $\log \mathrm{P}$ values of more than 2800 solute-alcohol solvent combinations to within standard deviations of $\mathrm{SD}=0.15$ and $\mathrm{SD}=0.16 \log$ units, respectively.

\section{ACKNOWLEDGMENT}

Mariam Saifullah and Shulin Ye thank the University of North Texas's Texas Academy of Math and Science (TAMS) program for a summer research award. 


\section{REFERENCES}

1. L. M. Sprunger, S. S. Achi, R. Pointer, W. E. Acree, Jr.; M. H. Abraham, Fluid Phase Equilibr., 288 (2010) 121-127.

2. L. M. Sprunger, S. S. Achi, R. Pointer, B. H. Blake-Taylor, W. E. Acree, Jr., M. H. Abraham, Fluid Phase Equilibr., 286 (2009) 170-174.

3. L. M. Sprunger, A. Proctor, W. E. Acree, Jr., M. H. Abraham, N. Benjelloun-Dakhama, Fluid Phase Equilibr., 270 (2008) 30-44.

4. M. H. Abraham, W. E. Acree, Jr., A. J. Leo, D. Hoekman, New J. Chem., 33 (2009) 568573.

5. M. H. Abraham, W. E. Acree, Jr.; J. E. Cometto-Muniz, New J. Chem., 33 (2009) 20342043.

6. M. H. Abraham, W. E. Acree, Jr., A. J. Leo, D. Hoekman, New J. Chem., 33 (2009) 1685-1692.

7. M. H. Abraham, W. E. Acree, Jr., J. Phys. Org. Chem., 21 (2008) 823-832.

8. L. M. Sprunger, S. S. Achi, W. E. Acree, M. H. Abraham, A. J. Leo, D. Hoekman, Fluid Phase Equilibr., 281 (2009) 144-162.

9. L. M. Sprunger, J. Gibbs, W. E. Acree, Jr., M. H. Abraham, Fluid Phase Equilibr., 273 (2008) 78-86.

10. M. H. Abraham, A. M. Zissimos, W. E. Acree, Jr., New J. Chem. 27 (2003) 1041-1044.

11. M. H. Abraham, A. M. Zissimos, W. E. Acree, Jr., Phys. Chem. Chem. Phys., 3 (2001) 3732-3736.

12. W. E. Acree, Jr., M. H. Abraham, J. Chem. Technol. Biotechnol., 81 (2006) 1441-1446.

13. M. H. Abraham, W. E. Acree, Jr., Green Chem., 8 (2006) 906-915. 
14. M. H. Abraham, A. Ibrahim, W. E. Acree, Jr., Eur. J. Med. Chem., 42 (2007) 743-751.

15. M. H. Abraham, A. Ibrahim, W. E. Acree, Jr., Eur. J. Med. Chem., 41 (2006) 494-502.

16. M. H. Abraham, A. Ibrahim, Y. Zhao, W. E. Acree, Jr., J. Pharm. Sci., 95 (2006) 20912100.

17. M. H. Abraham, A. Ibrahim, Eur. J. Med. Chem. 41 (2006) 1430-1438.

18. M. H. Abraham, A. Ibrahim, W. E. Acree, Jr., Chem. Res. Toxicol. 19 (2006) 801-808.

19. M. H. Abraham, R. Sanchez-Moreno, J. Gil-Lostes, W. E. Acree, Jr., J. E. ComettoMuniz, W. S. Cain, Toxicol. in Vitro, 24 (2010) 357-362.

20. M. H. Abraham, R. Sanchez-Moreno, J. E. Cometto-Muniz, W. S. Cain, Chem. Senses, 32 (2007) 711-719.

21. M. H. Abraham, M. Hassanisadi, M. Jalali-Heravi, T. Ghafourian, W. S. Cain, J. E. Cometto-Muniz, Toxicol. Sci., 76 (2003) 384-391.

22. L. M. Sprunger, A. Proctor, W. E. Acree, Jr., M. H. Abraham, Fluid Phase Equilibr., 265 (2008) 104-111.

23. L. M. Sprunger, M. Clark, W. E. Acree, Jr., M. H. Abraham, J. Chem. Inf. Model., 47 (2007) 1123-1129.

24. L. M. Sprunger, J. Gibbs, A. Proctor, W. E. Acree, Jr., M. H. Abraham, Y. Meng, C. Yao, J. L. Anderson, Ind. Eng. Chem. Res., 48 (2009) 4145-4154.

25. L. M. Sprunger, S. S. Achi, W. E. Acree, Jr., M. H. Abraham, Fluid Phase Equilibr., 288 (2010) 288,139-144.

26. A.-L. Revelli, F. Mutelet, J.-N. Jaubert, Ind. Eng. Chem. Res., 49 (2010) 3883-3892.

27. L. M. Sprunger, S. S. Achi, W. E. Acree, Jr., M. H. Abraham, Fluid Phase Equilibr., in press 
28. S. Endo, K.-U. Goss, Fluid Phase Equilibr., 291, 2010, 212-213.

29. B. H. Blake-Taylor, V. H. Deleon, W. E. Acree, Jr., M. H. Abraham, Phys. Chem. Liq., 45 (2007) 389-398.

30. C. R. Daniels, A. K. Charlton, R. M. Wold, W. E. Acree, Jr., M. H. Abraham, Can. J. Chem., 81 (2003) 1492-1501.

31. K. R. Hoover, D. M. Stovall, E. Pustejovsky, R. Coaxum, K. Pop, W. E. Acree, Jr., M. H. Abraham, Can. J. Chem. 82 (2004) 1353-1360.

32. K. R. Hoover, R. Coaxum, E. Pustejovsky, D. M. Stovall, W. E. Acree, M. H. Abraham, Phys. Chem. Liq., 42 (2004) 339-347.

33. K. M. De Fina, T. L. Sharp, W. E. Acree, Jr.. Can. J. Chem., 77 (1999) 1589-1593.

34. F.J. Carmona, V.R. Bhethanabotla, S.W. Campbell, J.A. Gonzalez, I.G. de la Fuente,J.C. Cobos, J. Chem. Thermodyn., 33 (2001) 47-59.

35. F.J. Carmona, J.A. Gonzalez, I. Garcia de la Fuente, J.C. Cobos, V.R. Bhethanabotla, S.W. Campbell, J. Chem. Eng. Data, 45 (2000) 699-703.

36. N.L. Alderson, V.R. Bhethanabotla, S.W. Campbell, J. Chem. Eng. Data, 48 (2003) 9296.

37. J.H. Park, A. Hussam, P. Couasnon, D. Fritz, P.W. Carr, Anal. Chem., 59 (1987) 19701976.

38. A. Henni, P. Tontiwachwuthikul, A. Chakma, Can. J. Chem. Eng., 83 (2005) 358-361.

39. M. H. Abraham, Chem. Soc. Reviews, 22 (1993) 73-83.

40. M. H. Abraham, A. Ibrahim, A. M. Zissimos, J. Chromatogr. A, 1037 (2004) 29-47.

41. C. E. Green, M. H. Abraham, W. E. Acree, Jr., K. M. De Fina, T. L. Sharp, Pest Manage. Sci., 56 (2000) 1043-1053. 
42. M. H. Abraham, R. E. Smith, R. Luchtefeld, A. J. Boorem, R. Luo, W. E. Acree, Jr., J. Pharm. Sci., 99 (2010) 1500-1515. 
Table 1. Experimental Mole Fraction Solubilities, $\mathrm{X}_{\mathrm{S}}{ }^{\text {sat }}$, of Crystalline Nonelectrolyte Solutes in Alkoxyalkanol Solvents at $298.15 \mathrm{~K}$

Solvent

$\mathrm{X}_{\mathrm{S}}^{\mathrm{sat}}$

Solute = 3-Methylbenzoic acid

2-Ethoxyethanol

0.2106

2-Propoxyethanol

0.2106

2-Butoxyethanol

0.2165

2-Isopropoxyethanol

0.2274

3-Methoxy-1-butanol

0.2055

1-tert-Butoxy-2-propanol

0.2257

Solute $=$ Salicylamide

2-Ethoxyethanol

0.1324

2-Propoxyethanol

0.1092

2-Butoxyethanol

0.0888

2-Isopropoxyethanol

0.1039

3-Methoxy-1-butanol

0.0849

1-tert-Butoxy-2-propanol

0.0992

Solute $=4$-Nitrobenzoic acid

2-Ethoxyethanol

0.0301

2-Propoxyethanol

0.0247

2-Butoxyethanol

0.0250 
2-Isopropoxyethanol

3-Methoxy-1-butanol

1-tert-Butoxy-2-propanol

0.0324

Solute $=2$-Methoxybenzoic acid

2-Ethoxyethanol

0.1193

2-Propoxyethanol

0.1052

2-Butoxyethanol

0.1301

2-Isopropoxyethanol

0.0850

3-Methoxy-1-butanol

0.1092

1-tert-Butoxy-2-propanol

0.0764

Solute $=4$-Methoxybenzoic acid

2-Ethoxyethanol

0.0412

2-Propoxyethanol

0.0333

2-Butoxyethanol

0.0384

2-Isopropoxyethanol

0.0361

3-Methoxy-1-butanol

0.0371

1-tert-Butoxy-2-propanol

0.0273

Solute $=4$-Chlorobenzoic acid

2-Ethoxyethanol

0.0337

2-Propoxyethanol

0.0309

2-Butoxyethanol

0.0299

2-Isopropoxyethanol

0.0354

Solute $=$ Biphenyl 
2-Ethoxyethanol

2-Propoxyethanol

2-Butoxyethanol

2-Isopropoxyethanol

3-Methoxy-1-butanol

Solute $=4$-Hydroxyacetanillide

2-Ethoxyethanol

2-Propoxyethanol

2-Butoxyethanol

2-Isopropoxyethanol

3-Methoxy-1-butanol

1-tert-Butoxy-2-propanol
0.1411

0.1683

0.1551

0.1613

0.1464

0.1251

0.0805

0.0613

0.0880

0.0673

0.0415 
Table 2. Fragment-Specific Equation Coefficients for the Abraham Model for Describing the Gas-to-Alcohol (Dry) Partition Coefficients of Solutes at 298 K

\begin{tabular}{|l|r|r|r|r|r|r|}
\hline Fragment Group & \multicolumn{1}{|c|}{$\mathrm{c}$} & \multicolumn{1}{c|}{$\mathrm{e}$} & \multicolumn{1}{c|}{$\mathrm{s}$} & \multicolumn{1}{c|}{$\mathrm{a}$} & \multicolumn{1}{c|}{$\mathrm{b}$} & \multicolumn{1}{c|}{$\mathrm{I}$} \\
\hline $\mathrm{CH}_{3}$ & 0.195 & -0.190 & 0.273 & 1.488 & 0.153 & 0.459 \\
\hline & $(0.024)$ & $(0.036)$ & $(0.052)$ & $(0.043)$ & $(0.066)$ & $(0.010)$ \\
\hline $\mathrm{CH}_{2}$ & -0.013 & 0.006 & -0.067 & -0.069 & -0.093 & 0.019 \\
\hline & $(0.002)$ & $(0.004)$ & $(0.005)$ & $(0.006)$ & $(0.007)$ & $(0.001)$ \\
\hline $\mathrm{CH}$ & -0.208 & 0.121 & -0.496 & -1.615 & -0.342 & -0.403 \\
\hline & $(0.030)$ & $(0.044)$ & $(0.062)$ & $(0.056)$ & $(0.080)$ & $(0.012)$ \\
\hline $\mathrm{C}$ & -0.344 & 0.219 & -0.771 & -3.050 & -0.725 & -0.831 \\
\hline & $(0.058)$ & $(0.088)$ & $(0.127)$ & $(0.115)$ & $(0.164)$ & $(0.022)$ \\
\hline $\mathrm{OH}$ & -0.195 & -0.071 & 0.700 & 2.491 & 1.172 & 0.362 \\
\hline & $(0.024)$ & $(0.036)$ & $(0.052)$ & $(0.044)$ & $(0.066)$ & $(0.010)$ \\
\hline $\mathrm{O}$ & -0.154 & -0.021 & 0.592 & -0.103 & -0.170 & -0.010 \\
\hline & $(0.043)$ & $(0.061)$ & $(0.092)$ & $(0.071)$ & $(0.118)$ & $(0.018)$ \\
\hline $\mathrm{C}(\mathrm{O}) \mathrm{O}$ & -0.209 & -0.006 & 0.886 & -0.149 & -0.120 & -0.025 \\
\hline & $(0.050)$ & $(0.075)$ & $(0.109)$ & $(0.091)$ & $(0.139)$ & $(0.020)$ \\
\hline $\mathrm{C}=\mathrm{O}$ & -0.261 & -0.015 & 1.071 & 0.000 & -0.159 & -0.030 \\
\hline & $(0.051)$ & $(0.080)$ & $(0.115)$ & & $(0.147)$ & $(0.020)$ \\
\hline
\end{tabular}


Table 3. Fragment-Specific Equation Coefficients for the Abraham Model for Describing the Hypothetical Water-to-Alcohol (Dry) Partition Coefficients of Solutes at 298 K

\begin{tabular}{|l|r|r|r|r|r|r|}
\hline Fragment Group & \multicolumn{1}{|c|}{$\mathrm{c}$} & \multicolumn{1}{c|}{$\mathrm{e}$} & \multicolumn{1}{c|}{$\mathrm{s}$} & $\mathrm{a}$ & \multicolumn{1}{c|}{$\mathrm{b}$} & \multicolumn{1}{c|}{$\mathrm{v}$} \\
\hline $\mathrm{CH}_{3}$ & 0.247 & 0.156 & -0.587 & -0.253 & -2.336 & 2.085 \\
\hline & $(0.028)$ & $(0.034)$ & $(0.052)$ & $(0.049)$ & $(0.070)$ & $(0.041)$ \\
\hline $\mathrm{CH}_{2}$ & -0.037 & 0.018 & -0.041 & -0.058 & -0.101 & 0.076 \\
\hline & $(0.003)$ & $(0.005)$ & $(0.006)$ & $(0.006)$ & $(0.008)$ & $(0.003)$ \\
\hline $\mathrm{CH}$ & -0.329 & -0.165 & 0.399 & 0.195 & 2.125 & -1.852 \\
\hline & $(0.037)$ & $(0.042)$ & $(0.062)$ & $(0.062)$ & $(0.084)$ & $(0.050)$ \\
\hline $\mathrm{C}$ & -0.548 & -0.384 & 1.037 & 0.489 & 4.179 & -3.824 \\
\hline & $(0.069)$ & $(0.087)$ & $(0.130)$ & $(0.127)$ & $(0.174)$ & $(0.090)$ \\
\hline $\mathrm{OH}$ & 0.019 & 0.234 & -0.323 & 0.581 & -1.178 & 1.667 \\
\hline & $(0.027)$ & $(0.034)$ & $(0.052)$ & $(0.049)$ & $(0.070)$ & $(0.040)$ \\
\hline $\mathrm{O}$ & -0.128 & 0.038 & 0.465 & -0.124 & 0.024 & -0.067 \\
\hline & $(0.053)$ & $(0.057)$ & $(0.092)$ & $(0.081)$ & $(0.126)$ & $(0.077)$ \\
\hline $\mathrm{C}(\mathrm{O}) \mathrm{O}$ & -0.131 & 0.012 & 0.809 & -0.234 & -0.037 & -0.132 \\
\hline & $(0.059)$ & $(0.072)$ & $(0.111)$ & $(0.103)$ & $(0.147)$ & $(0.082)$ \\
\hline $\mathrm{C}=\mathrm{O}$ & -0.203 & -0.033 & 1.043 & -0.184 & -0.054 & -0.133 \\
\hline & $(0.060)$ & $(0.078)$ & $(0.118)$ & $(0.113)$ & $(0.156)$ & $(0.083)$ \\
\hline
\end{tabular}




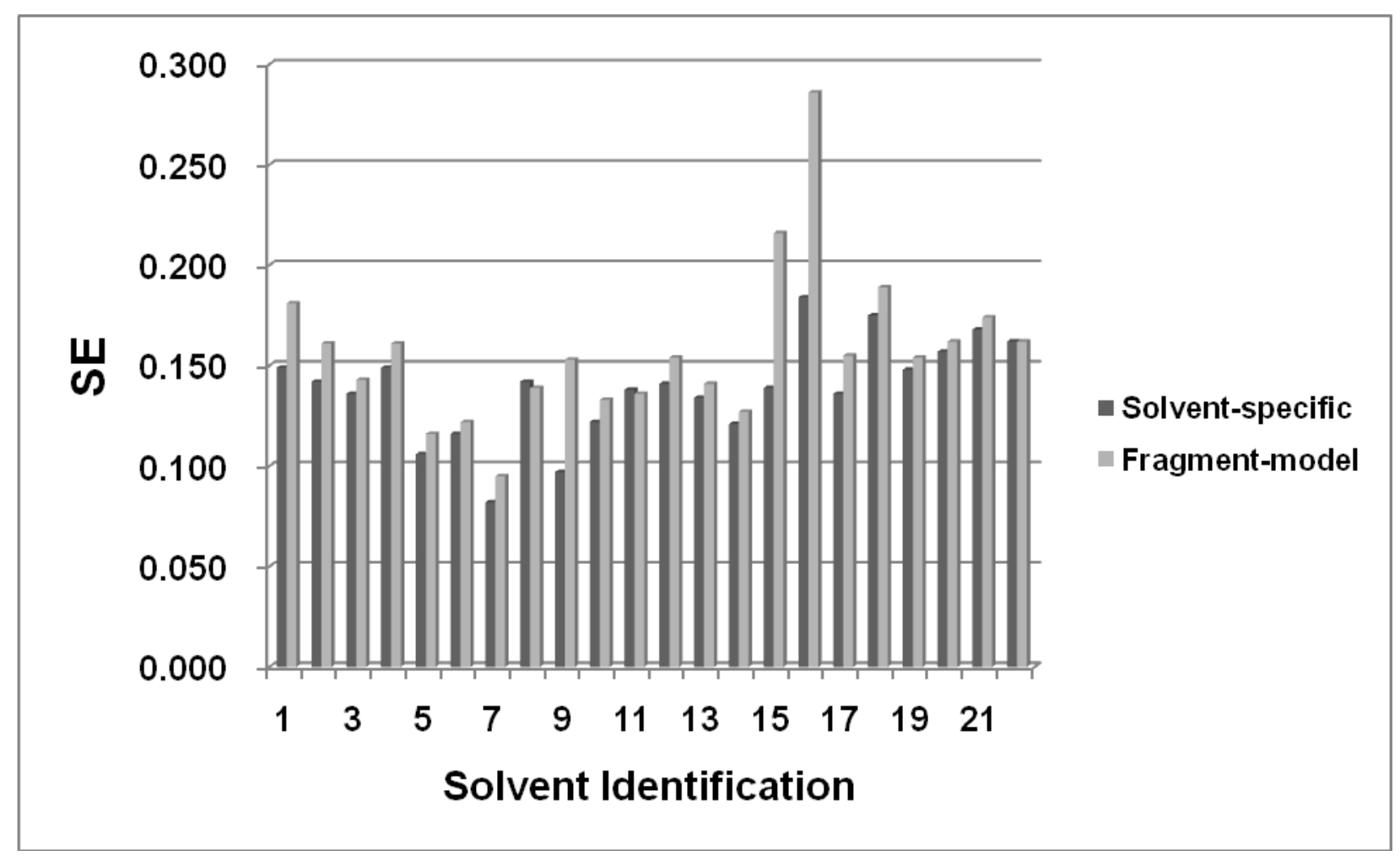

Figure 1. Summarized comparison of the mean standard errors for the solvent-specific Abraham model log K correlations (dark shading) versus calculated log K values based on the fragment-specific Abraham model (light shading). Solvent identities are as follows: (1) methanol; (2) ethanol; (3) 1-propanol; (4) 1-butanol; (5) 1-pentanol; (6) 1-hexanol; (7) 1-heptanol; (8) 1-octanol; (9) 1decanol; (10) 2-propanol; (11) 2-butanol; (12) 2-methyl-1-propanol; (13) 2-methyl-2-propanol; (14) 3-methyl-1-butanol; (15) diethyl 
ether; (16) dibutyl ether; (17) methyl tert-butyl ether; (18) methyl acetate; (19) ethyl acetate; (20) butyl acetate; (21) acetone; (22) 2butanone. 


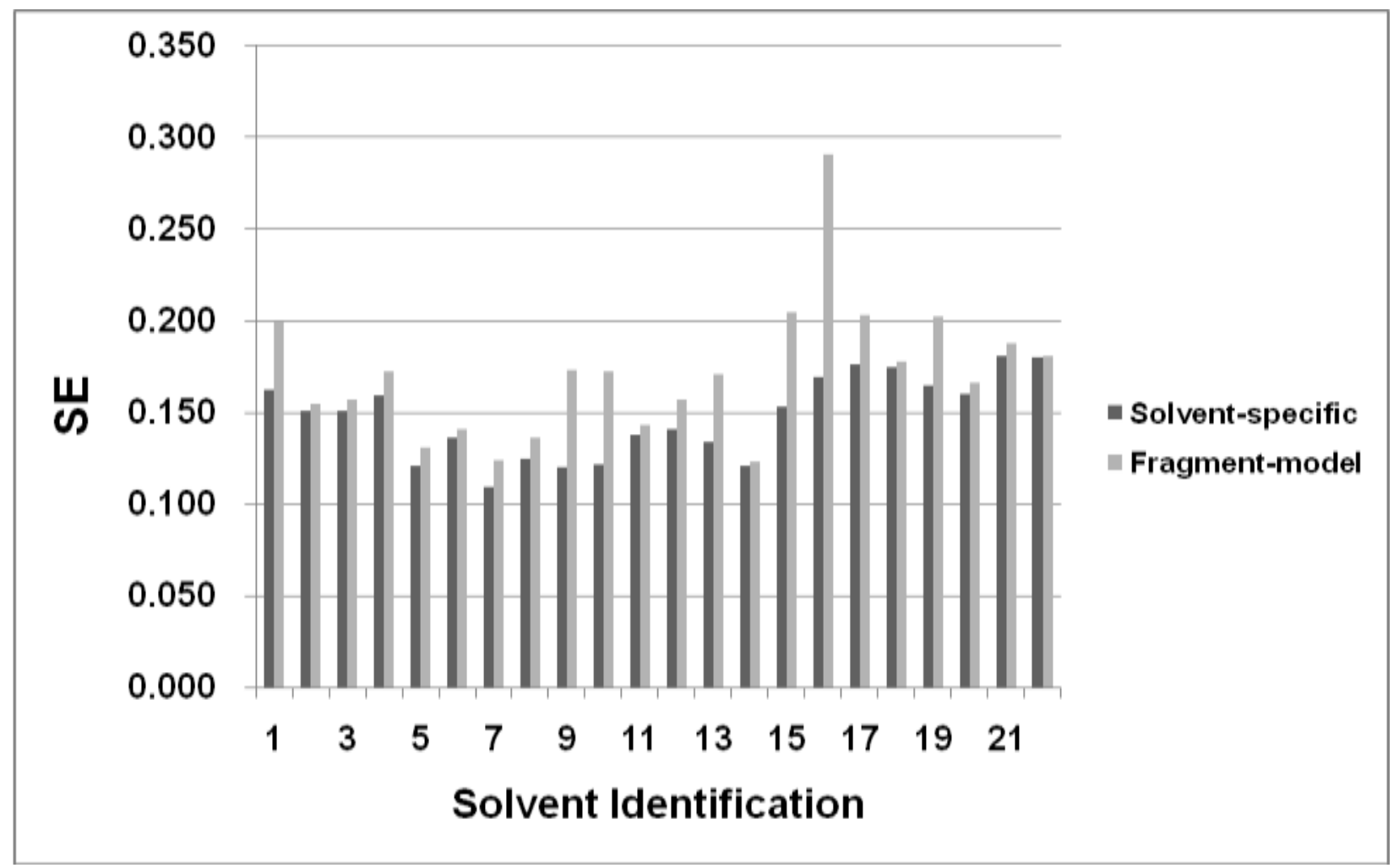

Figure 2. Summarized comparison of the mean standard errors for the solvent-specific Abraham model log P correlations (dark shading) versus calculated $\log \mathrm{P}$ values based on the fragment-specific Abraham model (light shading). Solvent identities are as follows: (1) methanol; (2) ethanol; (3) 1-propanol; (4) 1-butanol; (5) 1-pentanol; (6) 1-hexanol; (7) 1-heptanol; (8) 1-octanol; (9) 1decanol; (10) 2-propanol; (11) 2-butanol; (12) 2-methyl-1-propanol; (13) 2-methyl-2-propanol; (14) 3-methyl-1-butanol; (15) diethyl 
ether; (16) dibutyl ether; (17) methyl tert-butyl ether; (18) methyl acetate; (19) ethyl acetate; (20) butyl acetate; (21) acetone; (22) 2butanone. 